\title{
Antecedents of citizenship behaviour in online customer communities: An empirical investigation
}

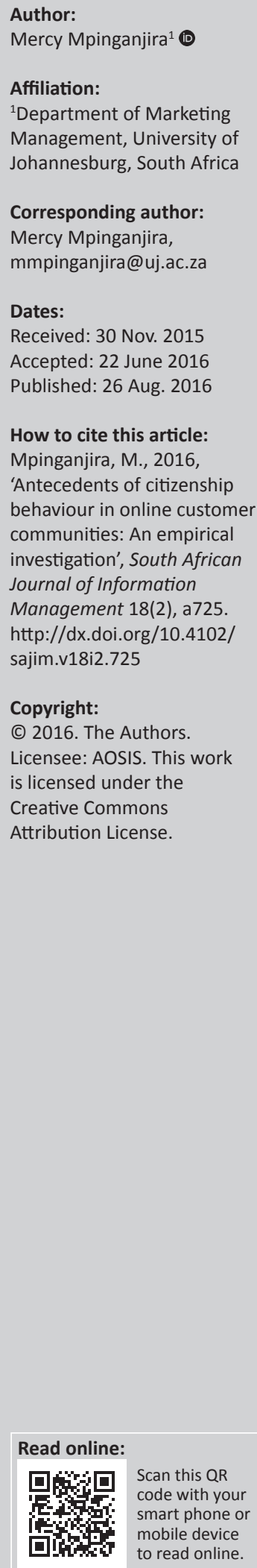

Background: Use of online communities for knowledge generation has become a common phenomenon. In order for online communities to serve as affective spaces for knowledge generation and exchange, members need to behave in ways that are in line with good citizenship. However, because of the limited research, not much is known about citizenship behaviour in such communities and the factors that foster such conduct.

Objectives: This article aims to examine the performance of citizenship behaviours by members of online customer communities, and the factors that influence this.

Methodology: Data were collected from 303 contributing members of online customer communities using a structured questionnaire. Structural equation modelling was used to analyse the data collected.

Results: The findings show moderate levels of engagement in citizenship behaviours among the respondents. Engagement in citizenship behaviours was in general found to be influenced more by the level of affective commitment towards the community than by the perceived levels of social support. Both affective commitment and perceived social support were found to have less influence on compliant citizenship behaviour when compared with altruism and personal initiative. Affective commitment was found to influence personal initiative most strongly, while social support had its strongest influence on altruism.

Conclusion: The results provide insights for managers of online customer communities into factors to which they should give attention in order to enhance the performance of citizenship behaviours.

\section{Introduction}

The evolution of the Internet over the years, and particularly the introduction of Web 2.0 technologies, has resulted in websites moving from being static pages to dynamic ones that allow users to generate content (Brake 2014:591). This has had a great impact on marketing activities, including market intelligence generation and sharing. O'Connor (2010:754) specifically points out that, as a result of Web 2.0, the Internet has evolved from being a medium for push marketing to one where 'peer-to-peer generation and sharing of data has become the norm'. Companies and consumers are increasingly developing websites on their own whose sole function is to facilitate group sharing of information. Zadeh and Sharda (2014:59) note that such sites, commonly known as online customer communities, have become a common phenomenon across industries. Online customer communities allow interested individuals to register on community websites, thereby gaining membership that allows them to connect with other members and share product- and service-related knowledge and experiences. Content generated on customer online community sites can be a useful source of intelligence for marketing decision-making (Chiu et al. 2015a:477).

Irrespective of whether an online community is company- or independently initiated, the ability of such sites to succeed as effective knowledge-sharing spaces largely depends on the collaborative efforts of their members. This is because how members interact on online community sites can influence their satisfaction with sites and their willingness to continue sharing knowledge (Chiu et al. 2011:144). Research shows that managers of online communities often struggle to attract and maintain significant numbers of contributors on their sites (Malinen 2015:228). Among the main reasons why users refrain from actively participating in online communities are issues of anti-social behaviour (Brandtzæg \& Heim 2008:15). Common examples of such behaviour on online community sites include intolerance, which can manifest itself in the use of sarcastic, indecent or inflammatory language in responding to other people's postings. Responses and comments posted on online community sites that attack other people's 
character - including making one feel grossly uninformed or incompetent - can be upsetting.

With online community sites becoming a growing point for generating business intelligence and considering the potential effect that the quality of interaction can have on knowledge sharing in such communities, the need for a better understanding of the factors that enhance prosocial behaviours on such platforms cannot be overemphasised. This article aims to contribute to this understanding by examining the performance of citizenship behaviours and their antecedents in online customer communities. It does so through the lens of social exchange theory.

The article has been structured such that the next section outlines the research problems and objectives of this study. This is followed by a review of the literature, and a presentation of the details of the methodology followed in conducting the study and of the results. Thereafter, conclusions drawn from the study are outlined before discussing their theoretical and managerial implications. Finally, the limitations of the study are presented, and suggestions for future research are offered before concluding the study.

\section{Research problem and objectives}

As social organisations, online community sites are bound to fail if member behaviour is not constructive and beneficial to the community as a whole and to its individual members. As noted by Chiu et al. (2015b:504), citizenship behaviour is about conduct that is prosocial - that is, it is known to promote the effective functioning of groups (Podsakoff et al. 2014:88). However, much research on citizenship behaviour is focused on employees in organisations (Gore, Kiefner \& Combs 2012:2434). Anaza (2014:251) further observes that while calls have been made to expand the research on citizenship behaviour including examining its manifestations in online contexts, research in this area is done predominantly from an offline perspective. By examining the concept of citizenship behaviour in the context of online customer communities and their precursors, this article contributes to addressing these gaps.

The article posits that citizenship behaviour in online customer communities manifests in varied and distinctive ways. Based on social exchange theory, the article further posits that citizenship behaviour in online customer communities is influenced by the perceived level of social support and by members' level of affective commitment towards their communities. Accordingly, the article proposes and tests a conceptual model that includes citizenship behaviour as a multidimensional construct and views social support and affective commitment as antecedents of citizenship behaviours. The specific objectives of the article are thus (1) to investigate levels of performance of citizenship behaviour by members of online customer communities; (2) to investigate the main dimensions of citizenship behaviour in online customer communities; (3) to examine the influence of social support on performance of citizenship behaviour in online customer communities; (4) to examine the influence of affective commitment on performance of citizenship behaviour in online customer communities; and (5) to test the relationship between social support and affective commitment in online customer communities.

\section{Theoretical framework and research hypotheses Citizenship behaviour}

Conceived by Bateman and Organ (1983), the concept of organisational citizenship behaviour (OCB) has its roots in the work of Barnard (1938), particularly in his argument on the importance of 'willingness to cooperate' for the effective functioning of an organisation (Markóczy, Vora \& Xin 2009:323). According to Organ (1990:44), Barnard's emphasis in his 1938 publication on the role of willingness to cooperate in explaining the effective functioning of organisations set him apart from the widely accepted thought of his day, which was in line with classical management theory. He noted that this theory presumes that individuals in an organisation lack the capacity or disposition to cooperate spontaneously and that only formal structures and controls enforced by management can ensure such behaviour. The argument advanced by Barnard in 1938 is that management's establishment and enforcement of formal structure and controls alone is not enough and that it needs the employees' willingness to cooperate to ensure optimal contributions for the effective functioning of organisations.

Since being proposed, the concept of OCB has been investigated by many researchers. A review of the literature, however, shows a lack of consensus on whether to conceptualise the construct as unidimensional or as multidimensional. Studies by Wong, Wong and Ngo (2012:287) and Van Knippenberg, Van Prooijen and Sleebos (2015:156), for example, examined organisational citizenship as a unidimensional construct, while Anaza (2014:254) and Boiral and Paillé (2012:435) took a multidimensional perspective. Commenting on the two approaches, Chiu et al. (2015b:505) argued for the multidimensional perspective, noting that - while it leads to complex research models - it helps to guard against a considerable loss of information about the relationship between different OCBs and other variables. Accordingly, this study takes a multidimensional approach in conceptualising citizenship behaviour in online customer communities. Anaza (2014:251) pointed out that customers exhibit different types of citizenship behaviours online. In the context of this study, it is of interest to examine the extent to which citizenship behaviours are distinct from one another and the relative influence of precursor factors on the different citizenship behaviours. This necessitated adopting a multidimensional perspective in examining citizenship behaviour. However, it is important to note that the literature shows that, even where the multidimensional approach is adopted, there are wide variations in what researchers consider to be important dimensions that manifest citizenship behaviour. 
Among the widely cited multidimensional conceptualisations of citizenship behaviour are those by Smith, Organ and Near (1983:657) and Organ (1988:4). Smith et al. (1983:657) noted that citizenship behaviour includes two main dimensions, which they called 'altruism' and 'compliance'. Altruism was presented to capture behaviour aimed at directly helping individual persons, while compliance was noted to be impersonal in that it encapsulates behaviour directed at the organisation or unit. Later, Organ (1988:4) distinguished five dimensions: altruism, conscientiousness, sportsmanship, courtesy and civic virtue. However, a meta-analysis of OCB studies conducted by LePine, Erez and Johnson (2002:52) found very high correlations between the five dimensions, indicating some overlaps that could compromise the discriminant validity of the dimensions. Another problem associated with the dimensions proposed by Organ (1988:4), as noted by Moon, Van Dyne and Wrobel (2005:2), is that they fail to capture behaviours that are change-oriented, such as innovativeness and taking personal initiative.

Commenting on the important dimensions of citizenship behaviour, Yu and Chu (2007:325) argued that researchers need to take into consideration the context under study in deciding which behaviours to focus on when measuring the construct. Considering the need to take into account both behaviours that directly benefit the organisation and those that directly benefit the individual, as well as the importance of capturing behaviours that denote pro-activeness, this study focuses on the dimensions of altruism, compliance and personal initiative. As online customer communities are meant to encourage engagement on consumer-related issues, the willingness of individuals to help other members by, for example, responding to consumption-related questions or concerns that they may have, is an important element of behaviour on such sites; hence, the inclusion of altruism as an important dimension of online customer community citizenship behaviour. Because engagement by its very nature means that individual members' conduct affects other members, their ready willingness to cooperate and to comply with community regulations and rules is an important attribute; hence, the inclusion of compliance. On the other hand, personal initiative is important in such a context, as it has the potential to ensure informed dialogue, thereby enhancing the quality of the knowledge generated.

As noted before, the underlying theory used in this study to examine citizenship behaviour and its antecedents is social exchange theory. The next section looks at this theory in some detail.

\section{Social exchange theory and the proposed conceptual model}

The social exchange theory 'focuses on voluntary exchanges of value by actors (people, organisations) in a social system' (Tanskanen 2015:578). Rooted in the works of Gouldner (1960), Homans (1958), and Blau (1964), the theory holds that all aspects of social life can be conceived of as a series of

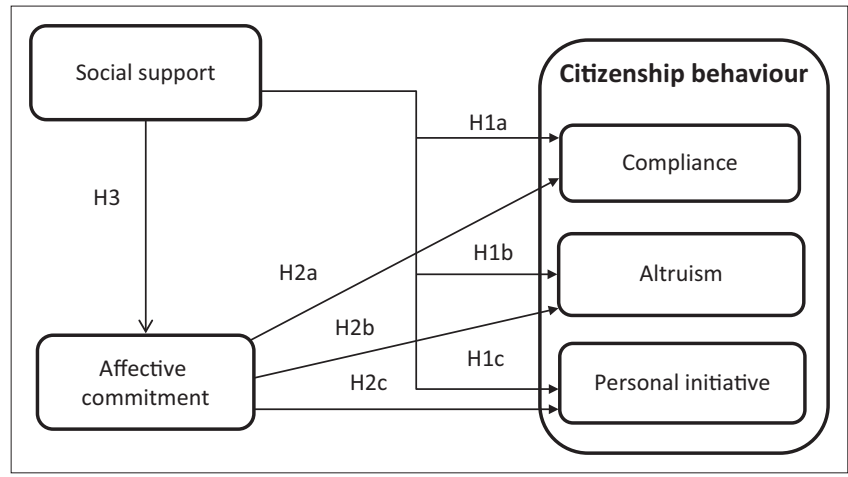

FIGURE 1: Organisational citizenship behaviour and its precursors in customer online communities.

exchanges involving tangible and intangible resources, with tangible and intangible benefits and costs (Chang et al. 2015:868). Examples of costs include time and energy spent in the course of social exchange. Benefits that one can derive from a social system include friendship, love, respect, the pleasure of being with another, information, status and honour (Chang et al. 2015:868; Liao 2008:1882). These benefits are core to the social exchange theory, serving as a source of positive reinforcement in relationships. Another important argument advanced by the theory is that social exchange follows a 'pattern of mutually contingent exchanges of gratification between parties' (Wong et al. 2012:279). In other words, the theory holds that beneficial acts towards another social actor are reciprocated through service and the expression of gratitude. For this reason, the concept of reciprocity is known to be central to social exchange theory (Tanskanen 2015:579).

Keeping in mind the fact that online customer communities are primarily there to serve as social spaces for interaction and to provide support to members, this study argues that the performance of customer citizenship behaviour is directly influenced by the levels of perceived support derived from a community. Wu, Chen and Chung (2010:1028) state that commitment is a behavioural outcome that is highly dependent on satisfaction, with benefits derived in exchange relations. Accordingly, this study includes commitment as a factor that is influenced by the perceived level of community support. Commitment is also postulated to have an impact on customer citizenship behaviour.

The subsections that follow discuss the constructs in the model and their proposed relationships (Figure 1).

\section{Social support and customer citizenship behaviour}

According to Van Knippenberg et al. (2015:153), the concept of 'perceived organisational support' is all about the extent to which an organisation is perceived to fulfil its role in social exchange relations. Studies by Chiu et al. (2015b:506) and Hajli (2014:19) have identified informational and emotional support as key benefits that people derive from online networks. The online community can thus be viewed as an organisation that serves as a source of knowledge 
resources that benefit individual members when shared. Online customer communities serve the particularly important role of assisting customers in their consumptionrelated decisions by shaping their perceptions of the products and services as well as firms.

The norm of reciprocity advanced in the social exchange theory points to the fact that organisational support, as a benefit that people derive from being members of an online customer community, should lead to a sense of obligation on the part of an individual to respond positively towards that community. Chiang and Hsieh (2012:186) provide empirical evidence in support of the positive relationship between organisational support and behavioural response. Even in varied contexts, the studies specifically found that organisational support exerts a significant positive influence on citizenship behaviour. A study conducted in the context of online communities by Chen, Chen and Farn (2010:200) found that information, service and social climate influenced member satisfaction and that this in turn exerted a positive influence on members' willingness to engage in citizenship behaviour. Taking into consideration that this study examines citizenship behaviour at the individual dimensional level, the hypotheses put forward are that:

H1a: There is a significant positive relationship between perceived level of social support and compliance in online customer communities.

H1b: There is a significant positive relationship between perceived level of social support and altruism in online customer communities.

H1c: There is a significant positive relationship between perceived level of social support and the taking of personal initiative in online customer communities.

\section{Affective commitment, customer citizenship behaviour, and social support}

Commitment is widely acknowledged in the literature to be critical for the development of long-term relations (Mpinganjira, Svensson \& Mysen 2015:455). A literature review shows that commitment can manifest itself emotionally as well as behaviourally through, for example, strong intentions to maintain membership (Zayas-Ortiz et al. 2015:94). The emotional manifestation of commitment, commonly referred to as affective commitment, shows psychological attachment to or identification with an organisation. Duarte (2015:2) notes that affective commitment causes people to remain in a relationship because 'they want to' and not because 'they have to'. Consequently, affective commitment is a good indicator of the quality of a relationship. Zayas-Ortiz et al. (2015:94) describe affective commitment as 'the most valued behaviour' in organisations. Xerri and Brunetto (2013:3166) observe that individuals who are affectively committed to an organisation are considered to be loyal, tend to be actively involved in organisational activities and to be concerned with organisational well-being, and consequently work to contribute to organisational goals. Taking cognisance of the importance of active membership for the survival of online communities, in looking at commitment this study accordingly focuses on affective commitment towards online community.

Findings by Zayas-Ortiz et al. (2015:101) show that commitment is actually a significant antecedent of OCB and that affective commitment has a particularly significant influence on such behaviour. The fact that affective commitment is associated with high levels of identification may help explain this. As noted by Chiu et al. (2015b:509), the more a person identifies with an organisation, the more likely they are to act in its best interests. Accordingly, it is hypothesised in this study that:

H2a: There is a significant positive relationship between affective commitment and compliance in online customer communities.

H2b: There is a significant positive relationship between affective commitment and altruism in online customer communities.

H2c: There is a significant positive relationship between affective commitment and the taking of personal initiative in online customer communities.

Furthermore, this study posits that the level of affective commitment is influenced by social support. This argument is in line with the social exchange theory, in that it also points to reciprocation. Affective commitment in this case can be viewed as a form of reciprocation for the benefit of social support. Studies by Im, Lee and Kim (2015:1) and by Wang, Kraut and Levine (2012:833) provided empirical evidence of the influence that support can have on commitment. They specifically found that, in organisations, the perceived level of support exerts a significant positive influence on commitment towards an organisation. Gutierrez, Candela and Carver (2012:1604) also found that beneficial relations result in commitment. Accordingly, it is hypothesised in this study that:

H3: There is a significant positive relationship between perceived level of social support and affective commitment in online customer communities.

\section{Methodology Research approach}

This article was part of a larger study of online customer communities. The study followed a quantitative research approach. The decision to take this approach was informed by the need to collect data from a large number of respondents and then to use it to test the hypotheses statistically. Zikmund and Babin (2012:92) note that the quantitative approach allows easy collection of data from a large number of respondents. They also note that the statistical testing of 
relationships between constructs requires data from a larger number of respondents than when non-statistical approaches are used to analyse data.

\section{Target population and sampling}

The target population for this study was individuals who contribute to discussions in online customer communities. The study was conducted in Gauteng, South Africa. Due to the need to ensure informed consent, only individuals aged 18 and above were allowed to participate in the study. As there was no list available of participants in customer online communities from which to draw a random sample, the study made use of a non-probability sampling method in the form of convenience sampling of selected respondents. Use of the convenience sampling method is common and widely accepted in business research, including studies in e-marketing. Carlson and O'Cass (2011:273) observe that studies have consistently shown that convenience sampling is an efficient and suitable method to adopt during data collection.

\section{Measures and data collection}

Data collection was done using a structured questionnaire. All constructs of interest in this study were adapted from the literature and operationalised as multi-item measures. This is because, unlike single-item measures, multi-item measures have the advantage of being more reliable and less prone to random measurement errors (Hahn 2011). Items used to measure compliance were specifically adapted from Fang and Chiu (2010:245) and Bell and Menguc (2002:146). Items used to measure altruism were adapted from Chen, Fan and Tsai (2014:172), and Ma and Chan (2014:57). Items used to measure personal initiative were adapted from studies by Choi (2007:476) and by Bateman and Crant (1993:112). Social support was measured using items adapted from Eisenberger et al. (1997:815) and Bell and Menguc (2002:146), while items used to measure affective commitment were adapted from Allen and Meyer (1990:6). The use of scales adapted from the literature helped to enhance the face validity of the measures. All the items were measured using a seven-point Likert scale that ranged from $1=$ very strongly disagree to $7=$ very strongly agree.

Trained research assistants were used to collect the data. Potential respondents were approached at various public places in Gauteng, including shopping malls and parking bays, and invited to participate in the study. Respondents were asked to keep one specific online customer community in mind when responding to the questions. By the end of the data collection period, a total of 303 usable questionnaires had been received.

\section{Sample characteristics}

The sample characteristics showed that $44.9 \%$ of the respondents were male and $55.1 \%$ were female respondents. Respondents aged between 18 and 29 totalled 58.6\%, with the remaining 41.4\% aged between 30 and 49. Respondents who indicated that they had been part of their online customer community for a period of no more than 3 years totalled $53.8 \%$, with $16.2 \%$ indicating that they had been part of their online customer community for less than 1 year. Of the $46.2 \%$ who indicated they had been part of their respective communities for more than 2 years, only $17.2 \%$ had been members for longer than 5 years. Respondents who indicated that their communities were company-initiated totalled $26.1 \%$, while $73.9 \%$ indicated theirs as independently initiated.

\section{Data analysis}

Version 22 of SPSS/AMOS software was used to analyse the data. The analysis stage followed a two-step process as advocated by Hair et al. (2010:730). The first step involved assessing the measurement model for goodness of fit, construct reliability and construct validity. The initial measurement model had five constructs and 18 indicator items. However, cross-loading problems were observed during the initial factor analysis involving one item under personal initiative and one under altruism. The two items had loadings greater than 0.3 on more than one factor. According to Hair et al. (2010:119), deletion of items is recommended when there is evidence of cross-loading. The final measurement model assessed thus had 5 factors and 16 items.

The second stage involved testing the structural model to examine the results of the hypothesised relationships between constructs. As recommended by Hair et al. (2010), multiple fit indices were used to assess the measurement model's goodness of fit. These included the normed chisquare value, the Goodness-of-Fit Index (GFI), the Adjusted Goodness-of-Fit Index (AGFI), the Comparative Fit Index (CFI), the Tucker-Lewis Index (TLI), and the Root Mean Square Error of Approximation (RMSEA). Construct reliability was assessed by examining composite reliability coefficients. Construct validity testing involved the assessment of convergent validity, discriminant validity and nomological validity. As recommended by Hair et al. (2010:695), convergent validity was assessed by examining factor loadings and Average Variance Extracted (AVE) scores. Just as with convergent validity, discriminant validity was assessed in two ways: (1) by comparing AVE scores with Maximum Shared Variance (MSV) scores; and (2) by comparing the square root of AVE scores with inter-construct correlation values. Nomological validity, on the other hand, was assessed by examining the correlation between the factors hypothesised in the model, as related to one another.

\section{Results}

\section{Assessment of the measurement model}

Results of the confirmatory factor analysis showed good fit when conducted on the 5 constructs and 16 indicator variables to test the measurement properties of the constructs 
in the conceptual model. Specifically, the results showed a chi-square statistic of 241.562 with 94 degrees of freedom and a significant $p$ value of 0.000 . The normed chi-square value was 2.570 , the GFI was 0.908 , the AGFI was 0.867 , the CFI was 0.953 , the TLI was 0.940 and the RMSEA was 0.072 . These statistics are within the recommended thresholds for good fit, following Gaskin (2015). Assessment of construct reliability (Table 1) showed that all constructs were reliable, as evidenced by composite reliability coefficients greater than 0.7. The actual values ranged from 0.884 to 0.888 , confirming high reliability, following Hair et al. (2010:710).

The results provide evidence of convergent validity, discriminant validity, and nomological validity (Table 2). With regard to convergent validity, the results show that all constructs had an AVE value of greater than 0.5, ranging from 0.641 to 0.726 . According to Hair et al. (2010:695), AVE values greater than 0.5 provideevidence of unidimensionality of constructs, confirming convergent validity. The results also show that the AVE value for each construct was greater than MSV (Table 3). Furthermore, the results show that the square root of AVE value for all factors was greater than inter-construct correlations. According to Hair et al. (2010:710), square roots of AVE values that are greater than inter-construct correlations provide evidence of discriminant validity. The inter-construct correlation coefficients (presented in Table 3) show that the correlations between the conceptual model's hypothesised relationships were all statistically significant. Following Hair et al. (2010:710), significant correlations between constructs hypothesised as such in a model provide evidence confirming nomological validity.

TABLE 1: Measurement items, reliability, and factor loadings.

\begin{tabular}{|c|c|c|}
\hline Constructs and items & Composite reliability & Factor loadings \\
\hline SS - Social support & 0.882 & - \\
\hline SS 1 - The online community cares about my opinions & - & 0.681 \\
\hline SS 2 - Help is available from the online community when I have a problem & - & 0.757 \\
\hline SS 3 - The online community offers suggestions when I need help & - & 0.776 \\
\hline SS 4 - The online community shows concern for me & - & 0.738 \\
\hline AC-Affective commitment & 0.844 & - \\
\hline AC 2-I am happy to spend time with the online community & - & 0.771 \\
\hline AC 3 - The online community has a great deal of personal meaning for me & - & 0.791 \\
\hline Compl-Compliance & 0.888 & - \\
\hline Compl 1 - I obey online community rules & - & 0.795 \\
\hline Compl 2-I comply with online community regulations & - & 0.846 \\
\hline Compl 3-I follow my online community participating procedures & - & 0.807 \\
\hline Altr - Altruism & 0.842 & - \\
\hline Altr $2-I$ am always ready to assist other members of the online community & - & 0.769 \\
\hline Altr 3 - I willingly help other members of the online community who have problems & - & 0.775 \\
\hline PI - Personal initiative & 0.869 & - \\
\hline PI 1 - I often suggest solutions to issues that members are unhappy about & - & 0.751 \\
\hline PI 2-I am driven to make a difference in this community & - & 0.816 \\
\hline PI 3-I have been a powerful force for constructive change through this online community & - & 0.803 \\
\hline
\end{tabular}

SS, social support; AC, affective commitment; Compl, compliance; Altr, altruism; $\mathrm{PI}$, personal initiative.

TABLE 2: Hypothesis test results.

\begin{tabular}{|c|c|c|c|c|c|c|}
\hline Predictor variable & Predicted variable & Applicable hypothesis & Standardised regression coefficient & Standard error & $p$ & Conclusion \\
\hline \multirow[t]{3}{*}{ Social support } & Compliance & $\mathrm{H} 1 \mathrm{a}$ & 0.190 & 0.073 & 0.011 & Hypothesis supported \\
\hline & Altruism & $\mathrm{H} 1 \mathrm{~b}$ & 0.236 & 0.062 & 0.000 & Hypothesis supported \\
\hline & Personal initiative & $\mathrm{H} 1 \mathrm{c}$ & 0.252 & 0.065 & 0.000 & Hypothesis supported \\
\hline \multirow[t]{3}{*}{ Affective commitment } & Compliance & $\mathrm{H} 2 \mathrm{a}$ & 0.522 & 0.078 & 0.000 & Hypothesis supported \\
\hline & Altruism & $\mathrm{H} 2 \mathrm{~b}$ & 0.674 & 0.068 & 0.000 & Hypothesis supported \\
\hline & Personal initiative & $\mathrm{H} 2 \mathrm{c}$ & 0.663 & 0.070 & 0.000 & Hypothesis supported \\
\hline Social support & Affective commitment & $\mathrm{H} 3$ & 0.598 & 0.071 & 0.000 & Hypothesis supported \\
\hline
\end{tabular}

TABLE 3: Descriptives, construct correlation and validity.

\begin{tabular}{lcccccc}
\hline Construct & Mean & Standard deviation & SS & AC & Compl & Altr \\
\hline SS & 5.55 & 1.173 & 0.808 & - & - & - \\
AC & 5.65 & 1.228 & 0.596 & 0.802 & - & - \\
Compl & 5.80 & 1.131 & 0.480 & 0.575 & 0.852 & - \\
Altr & 5.56 & 1.125 & 0.617 & 0.727 & 0.652 & 0.745 \\
PI & 5.58 & 1.189 & 0.627 & 0.745 & 0.480 \\
Average & - & - & 0.652 & 0.644 & 0.726 & 0.796 \\
MSV & - & - & 0.393 & 0.555 & 0.641 & 0.425 \\
\hline
\end{tabular}

SS, social support; AC, affective commitment; Compl, compliance; Altr, altruism; PI, personal initiative; MSV, maximum shared variance. 


\section{Hypothesis testing}

After validating the measurement model, the hypothesised relationships between the constructs were tested using Structural Equation Modelling. The results (presented in Table 2) show that social support has a significant influence on the performance of citizenship behaviours, evidenced by significant regression coefficients between social support and compliance $(\beta=0.190, p=0.011)$, social support and altruism ( $\beta=0.236, p=0.000)$ and social support and personal initiative $(\beta=0.252, p=0.000)$. Accordingly, hypotheses H1a, H1b and H1c are supported.

The results on affective commitment and citizenship behaviours (Table 2) also show significant regression coefficients of $\beta=0.522, p=0.000$ for the relationship between affective commitment and compliance; $\beta=0.674, p=0.000$ for the relationship between affective commitment and altruism; and $\beta=0.663, p=0.000$ for the relationship between affective commitment and personal initiative. The results thus provide support for hypotheses $\mathrm{H} 2 \mathrm{a}, \mathrm{H} 2 \mathrm{~b}$ and $\mathrm{H} 2 \mathrm{c}$. The results further show that social support exerts a significant positive influence on affective commitment $(\beta=0.598, p=0.000)$. Accordingly, Hypothesis 3 is supported.

\section{Discussion and implications}

This study has examined the performance of OCBs among members of online customer communities and factors that influence the performance of such behaviours. The empirical findings show that the performance of citizenship behaviours is moderate, evidenced by behavioural means ranging from 5.56 to 5.80 on a seven-point scale and that it is significantly influenced by the perceived level of social support and the level of affective commitment towards the community. These findings are consistent with assertions by Chiang and Hsieh (2012:186), who note that receipt of organisational support often elicits the norm of reciprocity on the part of beneficiaries. Studies by Gutierrez et al. (2012:4) and Wang et al. (2012:833) also observe the positive influence that beneficial exchange relations have on ensuring commitment. While both factors have a direct influence on citizenship behaviour, the regression weights make it evident that affective commitment has a stronger direct influence on citizenship behaviours than does perceived level of social support. Examination of the relationship between social support and affective commitment shows that social support has a strong positive influence on affective commitment, evidenced by regression weight (regression weight $=0.598 ; p=0.000$ ). This is in line with assertions by Zayas-Ortiz et al. (2015:101) that affective commitment has a strong influence on citizenship behaviour.

The findings in this study have wide managerial and theoretical implications that are highlighted below.

\section{Theoretical implications}

To date, a great deal of research on citizenship behaviour has focused mainly on relations in physical workplaces. Studies such as those by Podsakoff et al. (2014:87) and Zayas-Ortiz et al. (2015:91) observe that OCBs in such contexts help to foster an environment that is conducive to knowledge sharing, growth and innovation. While it cannot be disputed that employees are an important source of the knowledge that is needed for organisational effectiveness, developments in the capabilities of Internet technology, including the emergence of virtual communities, are making it possible for organisations and individuals to facilitate knowledge acquisition from more sources, including their customers. By focusing on online customer communities, this study provides a theoretical insight that is useful for understanding citizenship behaviour in such contexts.

In looking at organisational citizenship, the study focused on compliance, altruism and personal initiative. In their review of studies on citizenship behaviours, LePine et al. (2002:52) bemoaned the high correlation between citizenship behaviours; but the findings in this study provide empirical evidence that these three constructs are distinct citizenship behaviours that members of online customer communities exhibit.

By using a sample of online customer community members from South Africa, this study also contributes to knowledge about the dimensionality of citizenship from a cultural context that is different from the norm. As also noted by Alizadeh et al. (2012:502), many studies of OCBs are based on samples primarily drawn from Western countries, the United States in particular. Commenting on the problem of the lack of research into citizenship behaviours from other parts of the world, Alizadeh et al. (2012:502) stated: 'research on OCB measurement in other contexts ... is important because the dimensionality of an OCB measure used in different cultural contexts should not be taken for granted'.

Apart from looking at OCBs manifested in online customer communities, the study contributes further to the theory by uncovering the antecedents of such behaviours. The findings show that both the perceived level of social support and affective commitment have a direct positive influence on the performance of citizenship behaviours in online customer communities, with affective commitment having a stronger influence. While this is so, the importance of the perceived level of social support in organisational citizenship need not be undermined, bearing in mind the significant positive influence that it has on levels of affective commitment.

Finally, the findings in the study support social exchange theory in the context of online customer communities. Specifically, the findings show that managers can expect the benefits that members of the online customer communities receive to be reciprocated in the form of commitment and beneficial citizenship behaviours.

\section{Managerial implications}

The findings in this study can be used by managers of online customer communities to gain insight into the performance of citizenship behaviours on their community sites. The findings 
point to the need for managers to pay attention specifically to the extent to which their sites serve members as an important source of social support. As noted by Hajli (2014:19), the primary function of online communities is to provide social support to members. Managers of online customer sites need to realise that, as with any other service, the inability of their sites to meet user needs can result in dissatisfaction, which in turn can lead to a loss of members.

In order to ensure that their sites are perceived favourably in terms of social support, it is important that managers look for strategies that help to stimulate an exchange of informational and emotional support among members. One way in which managers could ensure this is by making use of seeding strategies to stimulate discussions (Dzinotyiweyi 2015:158). Site managers can seed their sites with topics that interest a lot of members or stimulate much debate which help to keep posts on their sites current and relevant. Members are likely to look forward to visiting such sites, as they will be assured of finding information that is current. Managers could also look into making sure that their sites have tools available that support higher levels of member engagement. For example, Chiu et al. (2015b:515) have remarked that sites that support the sharing of videos and photos, rather than just text, can help to strengthen levels of support in their online communities. Managers could also look into collaborating with prestigious guests, inviting them to visit their sites and engage with members. For example, managers of independent online customer communities advocating consumer rights could invite guests who are experts on consumer rights topics, such as consumer rights lawyers, to engage with customers and to stimulate discussion not only with the expert but also among members.

While virtual communities have the potential to serve as a source of social support to members, managers of online customer communities need to realise that, if not wellmanaged, such sites can easily have the opposite effect. The veil of anonymity can sometimes lead people to engage in anti-social behaviours online (Paul, Bowman \& Banks 2015:243). Therefore, the need for active moderation should not be underestimated. Apart from the active moderation of sites, managers need also to sell the values and vision of their sites to members. Members who appreciate the importance of knowledge sharing through a given platform, and thus of sharing in the community's values and vision, are more likely to support it than those who do not.

\section{Limitations and future research}

While offering theoretical and managerial insights into the topic of citizenship behaviours among members of online customer communities, the study is not without limitations. These provide opportunities for further research into the topic. These include, firstly, the fact that the study was conducted using a sample of respondents drawn from a limited geographical area in South Africa, namely Gauteng. Furthermore, the samples were drawn using a non-probability sampling method, specifically convenience sampling. While the use of convenience sampling methods is common and widely accepted among researchers in business, the use of non-probability sampling methods comes with problems of external validity, as they limit the extent to which results can be generalised to the wider population. Future research replicating the study in other areas in South Africa and beyond could assist in gaining more insight into the applicability of the proposed conceptual framework in other contexts.

Secondly, in looking at citizenship behaviours, the study focused on compliance, altruism and personal initiative. While there is no consensus in the literature on the important facets of citizenship behaviour, the three selected factors are only some of the different possible facets discussed in the literature. Therefore, future studies could include additional behaviours and examine the extent to which they are prevalent in online customer communities.

\section{Conclusion}

Online customer communities have the potential to serve as an important source of business intelligence for firms as well as a source of information for informed consumption-related decision-making. However, the ability of firms and customers to derive these benefits depends on the readiness and willingness of members to engage in citizenship behaviours. This entails making positive contributions and avoiding behaviours that are harmful to other individuals or to the organisation as a whole. From the findings in this study, it can be concluded that the extent to which members of online customer communities engage in citizenship behaviours largely depends on the perceived level of social support that they derive from the community, as well as the extent to which they are affectively committed to their community. Managers of online customer communities could use the findings in this study to come up with strategies that enhance their sites for effective knowledge sharing.

\section{Acknowledgements Competing interests}

The author declares that he has no financial or personal relationships which may have inappropriately influenced him in writing this article.

\section{References}

Alizadeh, Z., Darvishi, S., Nazari, K. \& Emami, M., 2012, 'Antecedents and consequences of organisational citizenship behaviour (OCB)', Interdisciplinary Journal of Contemporary Research in Business 3(9), 494-505.

Allen, N.J. \& Meyer, J.P., 1990, 'The measurement and antecedents of affective, continuance and normative commitment to the organization', Journal of OccupationalPsychology63(1),1-18.http://dx.doi.org/10.1111/j.2044-8325.1990. tb00506.x

Anaza, N.A., 2014, 'Personality antecedents of customer citizenship behaviors in online shopping situations', Psychology \& Marketing 31(4), 251-263. http://dx. doi.org/10.1002/mar.20692

Barnard, C., 1938, The functions of the executive, Harvard University Press, Cambridge, $\mathrm{MA}$

Bateman, T.S. \& Crant, J.M., 1993, 'The proactive component of organizational behavior: A measure and correlates', Journal of Organizational Behavior 14(2), 103-118. http://dx.doi.org/10.1002/job.4030140202 
Bateman, T.S. \& Organ, D.W., 1983, 'Job satisfaction and the good soldier: The relationship between affect and employee "citizenship"', Academy of Management Journal 26(4), 587-595. http://dx.doi.org/10.2307/255908

Bell, S.J. \& Menguc, B., 2002, 'The employee-organization relationship, organizational citizenship behaviors, and superior service quality', Journal of Retailing 78(2), 131-146. http://dx.doi.org/10.1016/S0022-4359(02)00069-6

Blau, P.M., 1964, Exchange and power in social life, John Wiley, New York.

Boiral, O. \& Paillé, P., 2012, 'Organizational citizenship behaviour for the environment: Measurement and validation', Journal of Business Ethics 109(4), 431-445. http:// dx.doi.org/10.1007/s10551-011-1138-9

Brake, D.R., 2014, 'Are we all online content creators now? Web 2.0 and digital divides', Journal of Computer-Mediated Communication 19(3), 591-609. http:// dx.doi.org/10.1111/jcc4.12042

Brandtzæg, P.B. \& Heim, J., 2008, 'User loyalty and online communities: Why members of online communities are not faithful', paper presented at the 2nd International Conference on Intelligent Technologies for Interactive Entertainment, Playa del Carmen, Cancun, Mexico, January 8-10, viewed 20 October 2015, from https:// www.researchgate.net/profile/Petter_Brandtzaeg/publication/247927823 User loyalty and online communities why members_of_online communities are not faithful/links/0046352a83619315ee000000.pdf

Carlson, J. \& O'Cass, A., 2011, 'Developing a framework for understanding e-service quality, its antecedents, consequences, and mediators', Managing Service Quality: An InternationalJourna/21(3), 264-286. http://dx.doi.org/10.1108/09604521111127965

Chang, H.H., Tsai, Y.C., Chen, S.H., Huang, G.H. \& Tseng, Y.H., 2015, 'Building long-term partnerships by certificate implementation: A social exchange theory perspective', Journal of Business \& Industrial Marketing 30(7), 867-879. http://dx.doi. org/10.1108/JBIM-08-2013-0190

Chen, H.L., Fan, H.L. \& Tsai, C.C., 2014, 'The role of community trust and altruism in knowledge sharing: An investigation of a virtual community of teacher professionals', Journal of Educational Technology \& Society 17(3), 168-179.

Chen, M.J., Chen, C.D. \& Farn, C.K., 2010, 'Exploring determinants of citizenship behavior on virtual communities of consumption: The perspective of social exchange theory', International Journal of Electronic Business Management 8(3), 195-205.

Chiang, C.F. \& Hsieh, T.S., 2012, 'The impacts of perceived organizational support and psychological empowerment on job performance: The mediating effects of organizational citizenship behavior', International Journal of Hospitality Management 31(1), 180-190. http://dx.doi.org/10.1016/j.ijhm.2011.04.011

Chiu, C., Chiu, N.H., Sung, R.J. \& Hsieh, P.Y., 2015a, 'Opinion mining of hotel customergenerated contents in Chinese weblogs', Current Issues in Tourism 18(5), 477-495. http://dx.doi.org/10.1080/13683500.2013.841656

Chiu, C.M., Huang, H.Y., Cheng, H.L. \& Sun, P.C., 2015b, 'Understanding online community citizenship behaviors through social support and social identity', International Journal of Information Management 35(4), 504-519. http://dx.doi. org/10.1016/j.ijinfomgt.2015.04.009

Chiu, C.M., Wang, E.T., Shih, F.J. \& Fan, Y.W., 2011, ‘Understanding knowledge sharing in virtual communities: An integration of expectancy disconfirmation and justice theories', Online Information Review 35(1), 134-153. http://dx.doi.org/10.1108/ 14684521111113623

Choi, J.N., 2007, 'Change-oriented organizational citizenship behavior: Effects of work environment characteristics and intervening psychological processes', Journal of Organizational Behavior 28(4), 467-484. http://dx.doi.org/10.1002/job.433

Duarte, M.B., 2015, 'Organisational and professional commitments: The influence in nurses' organisational citizenship behaviours', Tékhne 13(1), 2-11. http://dx.doi. nurses' organisational citizenship beh
org/10.1016/j.tekhne.2015.03.001

Dzinotyiweyi, M., 2015, 'Development of an iterative process model of e-facilitation to support lifelong learning', in D. Nwaozuzu \& S. Mnisi (eds.), Proceedings of the South Africa International Conference on Educational Technologies, Pretoria, South Africa, April 19-21, pp. 153-161.

Eisenberger, R., Cummings, J., Armeli, S. \& Lynch, P., 1997, 'Perceived organizational support, discretionary treatment, and job satisfaction', Journal of Applied Psychology 82(5), 812-820. http://dx.doi.org/10.1037/0021-9010.82.5.812

Fang, Y.H. \& Chiu, C.M., 2010, 'In justice we trust: Exploring knowledge-sharing continuance intentions in virtual communities of practice', Computers in Human Behavior 26(2), 235-246. http://dx.doi.org/10.1016/j.chb.2009.09.005

Gaskin, J., 2015, Confirmatory factor analysis, Gaskination's StatWiki, viewed 18 November 2015, from http://statwiki.kolobkreations.com

Gore, J.S., Kiefner, A.E. \& Combs, K.M., 2012, 'Personality traits that predict academic citizenship behaviour', Journal of Applied Social Psychology 42(10), 2433-2456. http://dx.doi.org/10.1111/j.1559-1816.2012.00948.x

Gouldner, A.W., 1960, 'The norm of reciprocity: A preliminary statement', American Sociological Review 25, 161-178. http://dx.doi.org/10.2307/2092623

Gutierrez, A.P., Candela, L.L. \& Carver, L., 2012, 'The structural relationships between organizational commitment, global job satisfaction, developmental experiences, work values, organizational support, and person-organization fit among nursing faculty', Journal of Advanced Nursing 68(7), 1601-1614. http://dx.doi. org/10.1111/j.1365-2648.2012.05990.x

Hahn, E., 2011, Multi-item scales and tests: Development and validation methods, viewed 17 November 2015, from http://www.feinberg.northwestern.edu/sites/ bcc/docs/2011-lectures/Lecture5hahnmultiitemscales.pdf

Hair, J.F., Black, W.C., Babin, B.J. \& Anderson, R.E., 2010, Multivariate data analysis: A global perspective, 7th edn., Prentice Hall, Upper Saddle River, NJ.

Hajli, M.N., 2014, 'The role of social support on relationship quality and social commerce', Technological Forecasting and Social Change 87, 17-27. http://dx.doi. org/10.1016/j.techfore.2014.05.012
Homans, G.C., 1958, 'Social behavior as exchange', American Journal of Sociology 63, 597-606. http://dx.doi.org/10.1086/222355

Im, S.B., Lee, M.Y. \& Kim, S.Y., 2015, 'Nurses' perception of organizational commitment, nursing work environment, and social support in a general hospital', Journal of Korean Academy of Nursing Administration 21(1), 1-9. http://dx.doi. org/10.11111/jkana.2015.21.1.1

LePine, J.A., Erez, A. \& Johnson, D.E., 2002, 'The nature and dimensionality of organizational citizenship behavior: A critical review and meta-analysis', Journal of Applied Psychology 87(1), 52-65. http://dx.doi.org/10.1037/0021-9010.87.1.52

Liao, L.F., 2008, 'Knowledge-sharing in R\&D departments: A social power and social exchange theory perspective', The International Journal of Human Resource Management19(10),1881-1895.http://dx.doi.org/10.1080/09585190802324072

Ma, W.W. \& Chan, A., 2014, 'Knowledge sharing and social media: Altruism, perceived online attachment motivation, and perceived online relationship commitment', Computers in Human Behavior 39, 51-58. http://dx.doi.org/10.1016/j. chb.2014.06.015

Malinen, S., 2015, 'Understanding user participation in online communities: A systematic literature review of empirical studies', Computers in Human Behavio 46, 228-238. http://dx.doi.org/10.1016/j.chb.2015.01.004

Markóczy, L., Vora, D. \& Xin, K., 2009, 'Forbearance in organizational citizenship behaviour', The International Journal of Human Resource Management 20(2), 321-347. http://dx.doi.org/10.1080/09585190802670706

Moon, H., Van Dyne, L. \& Wrobel, K., 2005, 'The circumplex model and the future of organizational citizenship research', in D. Turpinseed (ed.), A handbook on organizational citizenship behavior: A review of 'good soldier' activity in organizations, Nova Science Publishers, New York.

Mpinganjira, M., Svensson, G. \& Mysen, T., 2015, 'META-RELQUAL construct validation: A South African study', African Journal of Economic and Management Studies 6(4), 453-465. http://dx.doi.org/10.1108/AJEMS-01-2013-0011

O'Connor, P., 2010, 'Managing a hotel's image on TripAdvisor', Journal of Hospitality Marketing \& Management 19(7), 754-772. http://dx.doi.org/10.1080/19368623. 2010.508007

Organ, D.W., 1988, Organizational citizenship behavior: The good soldier syndrome, Lexington Books, Lexington, MA.

Organ, D.W., 1990, 'The motivational basis of organizational citizenship behavior', Research in Organizational Behavior 12(1), 43-72.

Paul, H.L., Bowman, N.D. \& Banks, J., 2015, 'The enjoyment of griefing in online games', Journal of Gaming \& Virtual Worlds 7(3), 243-258. http://dx.doi. org/10.1386/jgvw.7.3.243_1

Podsakoff, N.P., Podsakoff, P.M., MacKenzie, S.B., Maynes, T.D. \& Spoelma, T.M., 2014 'Consequences of unit-level organizational citizenship behaviors: A review and recommendations for future research', Journal of Organizational Behavior 35(S1) S87-S119. http://dx.doi.org/10.1002/job.1911

Smith, C.A., Organ, D.W. \& Near, J.P., 1983, Organizational citizenship behavior: Its nature and antecedents, Journal of Applied Psychology 68(4), 653-663. http:// dx.doi.org/10.1037/0021-9010.68.4.653

Tanskanen, K., 2015, 'Who wins in a complex buyer-supplier relationship? A social exchange theory based dyadic study', International Journal of Operations \& Production Management 35(4), 577-603. http://dx.doi.org/10.1108/IJOPM-102012-0432

Van Knippenberg, D., Van Prooijen, J.W. \& Sleebos, E., 2015, 'Beyond social exchange: Collectivism's moderating role in the relationship between perceived organizational support and organizational citizenship behaviour', European Journal of Work and Organizational Psychology 24(1), 152-160. http:///dx.doi.org /10.1080/1359432X.2013.858699

Wang, Y.C., Kraut, R. \& Levine, J.M., 2012, 'To stay or leave? The relationship of emotional and informational support to commitment in online health support groups', in Proceedings of the ACM 2012 Conference on Computer Supported Cooperative Work, Seattle, WA, February 11-15, pp. 833-842.

Wong, Y.T., Wong, C.S. \& Ngo, H.Y., 2012, 'The effects of trust in organisation and perceived organisational support on organisational citizenship behaviour: A test of three competing models', The International Journal of Human Resource Management 23(2), 278-293. http://dx.doi.org/10.1080/09585192.2011.610966

Wu, J.J., Chen, Y.H. \& Chung, Y.S., 2010, 'Trust factors influencing virtual community members: A study of transaction communities', Journal of Business Research 63(9), 1025-1032. http://dx.doi.org/10.1016/j.jbusres.2009.03.022

Xerri, M.J. \& Brunetto, Y., 2013, 'Fostering innovative behaviour: The importance of employee commitment and organisational citizenship behaviour', The International Journal of Human Resource Management 24(16), 3163-3177. http://dx.doi.org/10.1080/09585192.2013.775033

Yu, C.P., \& Chu, T.H., 2007, 'Exploring knowledge contribution from an OCB perspective', Information \& Management 44(3), 321-331. http://dx.doi. org/10.1016/j.im.2007.03.002

Zadeh, A.H. \& Sharda, R., 2014, 'Modelling brand post popularity dynamics in online social networks', Decision Support Systems 65, 59-68. http://dx.doi.org/10.1016/j. dss.2014.05.003

Zayas-Ortiz, M., Rosario, E., Marquez, E. \& Gruñeiro, P., 2015, 'Relationship between organizational commitments and organizational citizenship behaviour in a sample of private banking employees', International Journal of Sociology and Social Policy of private banking employees', International Journal of Sociology
35(1/2), 91-106. http://dx.doi.org/10.1108/IJSSP-02-2014-0010

Zikmund, W.G. \& Babin, B.J., 2012, Essentials of marketing research, 5th edn., Cengage Learning, Mason, $\mathrm{OH}$. 